Jurnal Inkofar * Volume 1 No. 2, Desember 2018 * ISSN: 2615-3645 (Print) / 2581-2920 (Online)

Tersedia secara online di: http://www.politeknikmeta.ac.id/meta/ojs/

\title{
PERANCANGAN APLIKASI PENJUALAN RETAIL BERBASIS DEKSTOP PADA CV. HAMBALI KOPERPU
}

\author{
Cepi Cahyadi ${ }^{1}$, Manase Sahat H Simarangkir ${ }^{2}$ \\ ${ }^{1}$ Sistem Informasi / Program S1 / STMIK Nusa Mandiri / cepi.ccd@bsi.ac.id \\ ${ }^{2}$ Teknik Komputer / Program D3 / Politeknik Meta Industri Cikarang / \\ manasemalo@politeknikmeta.ac.id
}

\begin{abstract}
CV. Hambali Koperpu is a business in the field of drinking water, the existing sales system is still conventional, namely buying and selling transactions to the manufacture of transaction reports and customer data still using the book media recorded in each transaction, besides that it also often causes some problems due to files that lost With the use of computer technology that is using a special program created at CV. Hambali is a desktop application for Drinking Water Retail Sales Program and is designed using Microsoft Visual Basic 6.0 programming language and MySQL database as a data base server, with this application facilitating business activities in CV. Hambali and minimize errors that may arise in conventional systems. The transaction process to making reports and customer data can be resolved properly so that it resolves the problems that exist in the CV. Hambali Koperpu.
\end{abstract}

Keywords: Program, Application, Water Sales, Microsoft Visual Basic 6.0, Mysql

\begin{abstract}
ABSTRAK
CV. Hambali Koperpu adalah merupakan usaha dibidang air minum, sistem penjualan yang ada masih dengan konvensional yaitu transaksi jual beli hingga pembuatan laporan-laporan transaksi dan data pelanggan masih menggunakan media buku yang dicatat disetiap transaksi penjulanannya selain itu juga sering menimbulkan beberapa masalah dikarenakan berkas-berkas yang hilang. Dengan penggunaan teknologi komputer yaitu menggunakan program khusus yang dibuat di CV. Hambali berupa aplikasi desktop Program Penjualan Retail Air Minum dan didesain dengan menggunakan bahasa pemrograman Microsoft Visual Basic 6.0 dan database MySQL sebagai server data base, dengan adanya apliaksi ini memudahkan kegiatan usaha di CV. Hambali dan meminimalisir kesalahan yang mungkin timbul pada sistem konvensional. Proses transaksi hingga pembuatan laporan dan data pelanggan dapat diselesaikan dengan baik sehingga mengatasi permasalahan yang ada pada CV. Hambali Koperpu.
\end{abstract}

Kata Kunci : Program, Aplikasi, Penjualan Air Minum, Microsoft visual Basic 6.0, Mysql

\section{PENDAHULUAN}

Para pelaku bisnis informasi yang akurat dan tepat waktu akan membantu dalam mengambil keputusan dan menentukan langkah-langkah yang harus dilakukan untuk mempertahankan dan mengembangkan usaha bisnisnya dan informasi juga bagian yang penting dan berharga dalam dunia bisnis. Maka untuk semua itu dibutuhkan suatu pengolahan data yang handal, akurat, dan ditampilkan secara tepat dan mudah setiap kali diperlukan.

CV Hambali Koperpu adalah Toko yang dikelola oleh seorang pengusaha melakukan kegiatan jual beli air minum kemasan mineral sampai isi ulang air, Penjualan yang dilakukan oleh CV Hambali Koperpu secara konvensional yaitu seluruh kegiatan transaksi jual beli menggunakan media buku sebagai penyimpanan data dari transaksi- transaksi penjualannya. 
Jurnal Inkofar * Volume 1 No. 2, Desember 2018 * ISSN: 2615-3645 (Print) / 2581-2920 (Online)

Tersedia secara online di: http://www.politeknikmeta.ac.id/meta/ojs/

Dengan sistem yang terkomputerisasi sistem penjualan yang ada di CV Hambali akan menjadi efektif, efisien, dan akurat untuk memberikan pelayanan transaksi. Dengan demikian, sudah menjadi sebuah tuntutan bagi CV Hambali Koperpu untuk selalu mengikuti bahkan harus bisa mengiringi perkembangan teknologi informasi sehingga dapat meningkatkan produktivitas, efisiensi kerja, dan kemampuan CV Hambali Koperpu dalam bidang ekonomi.

\section{LANDASAN TEORI}

\subsection{Penelitian Terdahulu}

Pada penelitian sebelumnya di lakukan oleh Andi Muh. Lukman (2016) pada jurnal Ilmiah ILKOM, Perancangan Aplikasi Berbasis dekstop yang dirancang bersifat statis, desainnya menggunakan program java, dan Mysql sebagai server local membuat database, membuat halaman, mendesain warna, membuat link, menginput informasi, sehingga didapatkan hasil akhir dari pendesainan program berbasis desktop.

\subsection{Program}

Menurut Kadir (2012:2) program dapat diartikan "Kumpulan instruksi yang digunakan untuk mengatur komputer agar melakukan tindakan tertentu".

\subsection{Aplikasi}

Menurut Nazrudin Safaat H (2012:9) Perangkat lunak aplikasi adalah suatu subkelas perangkat lunak komputer yang memanfaatkan kemampuan komputer langsung untuk melakukan suatu tugas yang diinginkan pengguna.

\subsection{Microsoft Visual Basic}

Menurut Budi (2010:3) "Microsoft Visual Basic 6.0 adalah software untuk membuat program berbasis Windows".

\subsection{Basis data}

Menurut Pahlevi (2013:1) "Basis data adalah sekumpulan data yang saling berhubungan secara logis dan terorganisir dengan baik.

Basis data menurut Jeperson Hutahean (2014:50), merupakan kegiatan sistem program komputer untuk berbagi aplikasi komputer.

Menurut Anhar (2010:45) “Database adalah sekumpulan tabel-tabel yang berisi data dan merupakan kumpulan dari field atau kolom. Struktur file yang menyusun sebuah database adalah Data Record dan Field".

2.6 MYSQL

Menurut Sunarfrihantono(2002) MySQL adalah multiuser database yang menggunakan bahasa Structured Query Language (SQL).

\section{METODE PENELITIAN}

3.1 Model waterfall menurut Rosa dan Shalahudin (2015:28) sering juga disebut model sekuensial linier (sequential linear) atau alur hidup klasik (classic life cycle). Model air terjun menyediakan pendekatan alur hidup perangkat lunak secara sekuensial atau terurut dimulai dari analisis, desain, pengodean, pengujian, dan tahap pendukung (support) 
Jurnal Inkofar * Volume 1 No. 2, Desember 2018 * ISSN: 2615-3645 (Print) / 2581-2920 (Online)

Tersedia secara online di: http://www.politeknikmeta.ac.id/meta/ojs/

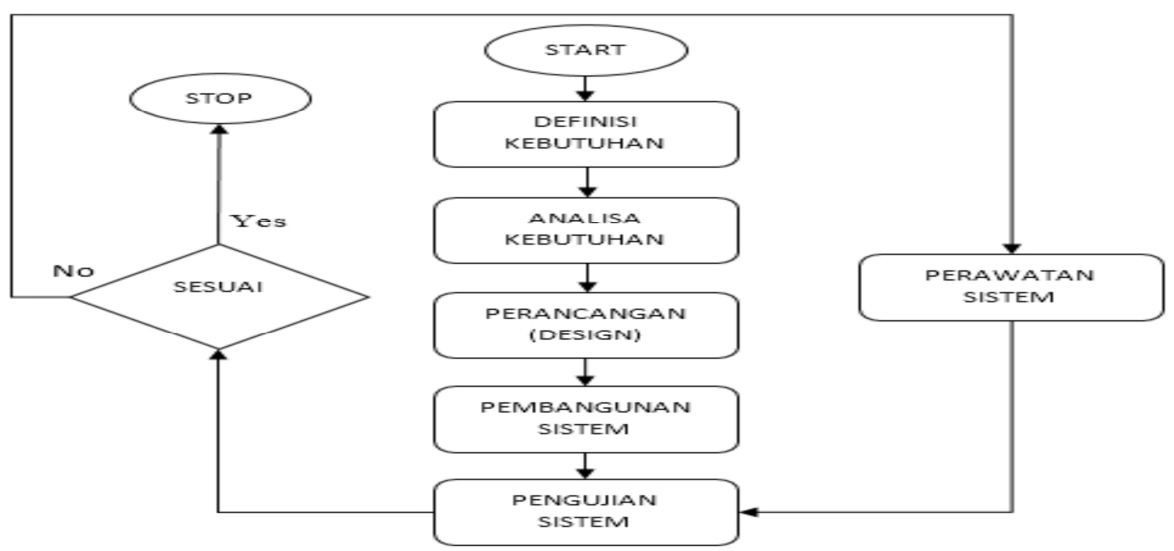

Gambar 1. alur waterfall

3.2 Metode Deskriptif suatu metode yang mengambarkan suati fenomena kegiatan yang terjadi didalam Deskriptif, dimana penelitian dimaksudkan untuk membuat penyandraan secara sistematis, faktual dan akurat mengenai fakta-fakta dan sifat-sifat populasi tertentu (Akbar, 2003:4).

\section{PEMBAHASAN}

Dari hasil analisa kebutuhan yang didapat di CV Hambali Koperpu proses sistem penjualaan yang knvensional akan berubah menjadi secara terkomputerisasi yaitu denga program Aplikasi penjualan air minum berbasis desktop.

Menurut Sukamto dan Shalahuddin (2013:28), "Model air terjun menyediakan pendekatan alur hidup perangkat lunak secara sekuensial atau terurut dimulai dari analisis, desain, pengkodean, pengujian, dan tahap pendukung (support)".

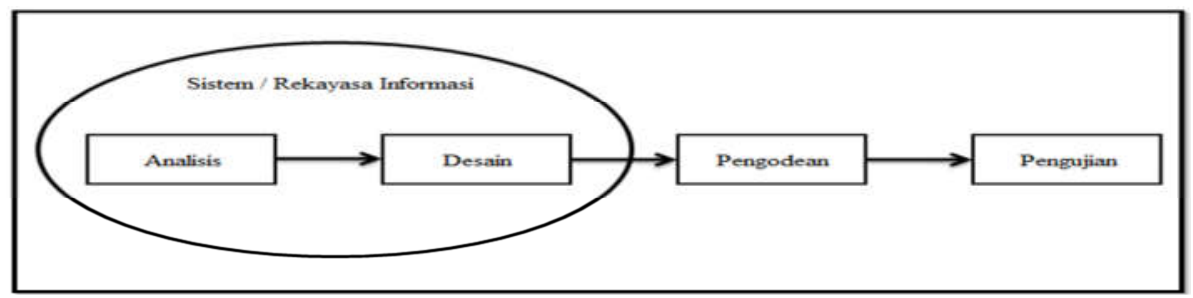

Gambar 2. alur waterfall

Alur desain sistem perancangan perangkat lunak sebagai berikut:

A. Analisa Kebutuhan

Analisa kebutuhan program ada dua pengguna yang mempunyai akses level berbeda, yang pertama akses level sebagai administrator dan kedua sebagai kasir. Berikut adalah akses yang dapat dilakukan oleh masing-masing pengguna:

1. Akses level sebagai Administrator

a. Input yaitu admin input adalah data transaksi, data barang, data pelanggan, data pembayaran tagihan, data pembelian, data pengeluaran, data user, menentukan biaya antar, menentukan jumlah promo kupon, menentukan jumlah minimal pembelian grosir serta menentukan target penjualan bulanan.

b. Output disini adalah yang dihasilkan berupa laporan transaksi, laporan pembelian, laporan pengeluaran, laporan data pelanggan, laporan data barang, laporan keuangan, kartu pelanggan dan kartu user.

2. Akses level sebagai Kasir

a. Input Yang dapat kasir input adalah data transaksi, data pelanggan, data pembayaran tagihan serta ubah password untuk akunnya tersebut.

b. Output Output yang dihasilkan berupa struk pembayaran dan kartu pelanggan. 
Jurnal Inkofar * Volume 1 No. 2, Desember 2018 * ISSN: 2615-3645 (Print) / 2581-2920 (Online) Tersedia secara online di: http://www.politeknikmeta.ac.id/meta/ojs/

\section{SPESIFIKASI PROGRAM}

\subsection{HIPO (Hierarchy Input Process Output)}

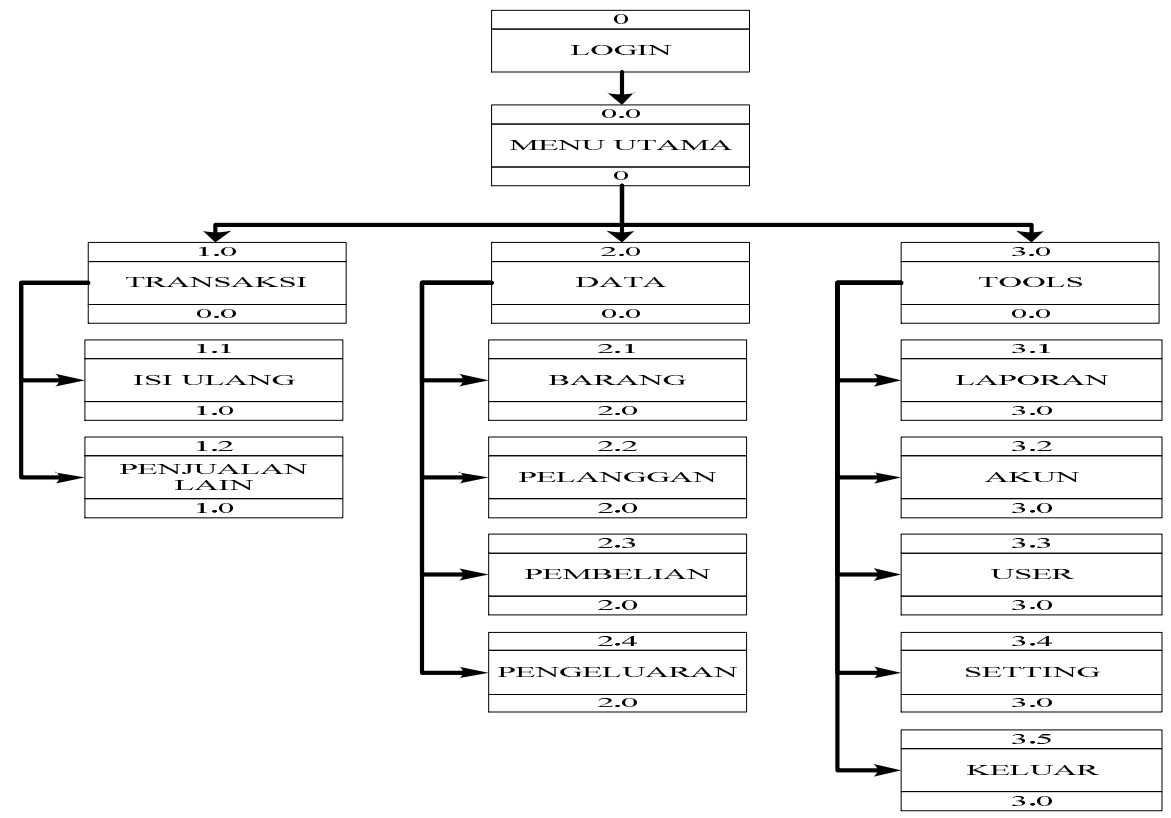

Gambar 3. HIPO. Sumber: Hasil Penelitian (2018)

\section{PERANCANGAN BASIS DATA}

\subsection{Entiny Relationship Diagram (ERD)}

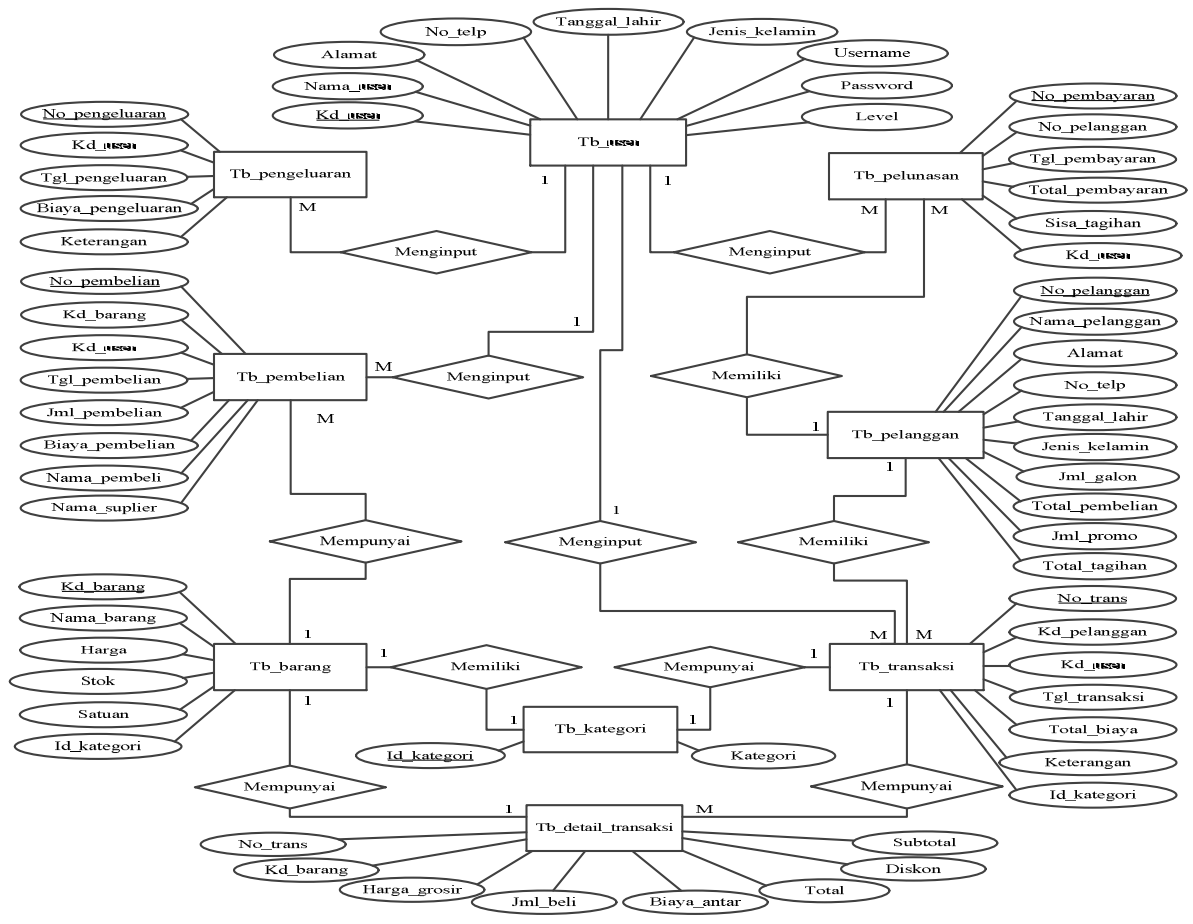

Gambar 4. ERD. Sumber: Hasil Penelitian (2018) 
Jurnal Inkofar * Volume 1 No. 2, Desember 2018 * ISSN: 2615-3645 (Print) / 2581-2920 (Online) Tersedia secara online di: http://www.politeknikmeta.ac.id/meta/ojs/

\subsection{LRS}

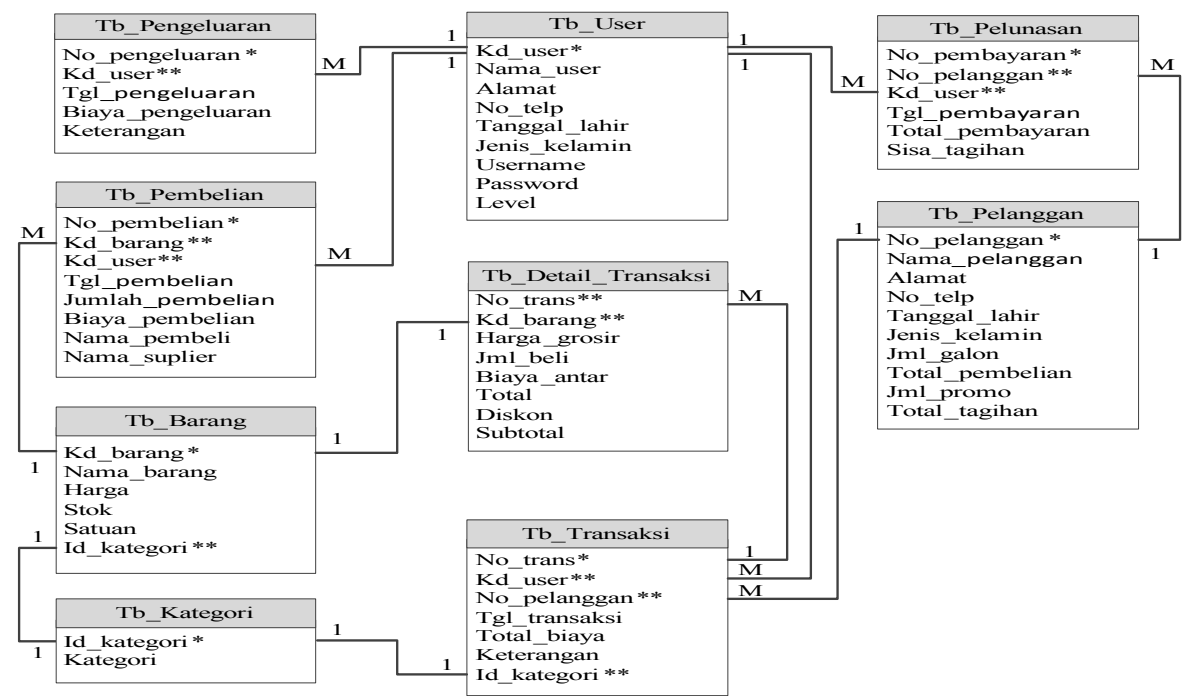

Gambar 5. LRS. Sumber: Hasil Penelitian (2018)

\subsection{Pengkodean}

Panjang : 11 Digit

Type : Karakter

\begin{tabular}{|l|l|l|l|l|l|l|l|l|l|l|}
\hline $\mathrm{T}$ & $\mathrm{R}$ & 1 & 7 & $\mathrm{O}$ & 6 & 3 & 0 & 1 & 2 & 3 \\
\hline
\end{tabular}

Gambar 6. Pengkodean

Ket :

TR : Menunjukkan inisial Transaksi

17 : Menunjukkan tahun Transaksi

06 : Menunjukkan bulan Transaksi

30 : Menunjukkan tanggal Transaksi

123 : Menunjukkan nomor urut Transaksi

\section{IMPLEMENTASI DAN PENGUJIAN UNIT}

\subsection{Menu Login}

Halaman login merupakan halaman menu untuk masuk ruang aplikasi.

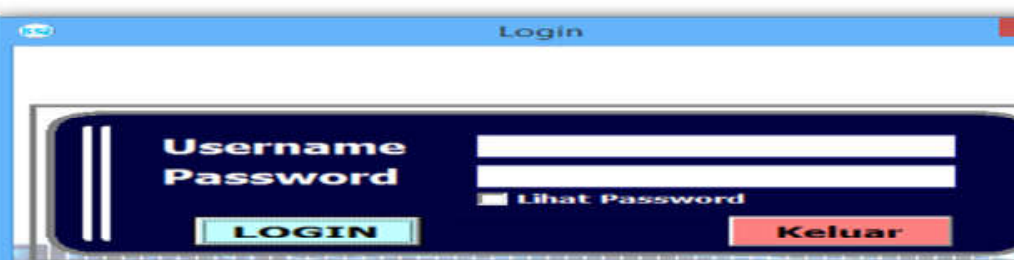

Gambar 7. Menu Login 
Jurnal Inkofar * Volume 1 No. 2, Desember 2018 * ISSN: 2615-3645 (Print) / 2581-2920 (Online)

Tersedia secara online di: http://www.politeknikmeta.ac.id/meta/ojs/

\subsection{Menu Utama}

Halaman Menu Utama merupakan halaman menu yang menjadi tampilan utama aplikasi.

Pada halaman ini menampilkan semua menu yang dibutuhkan user.

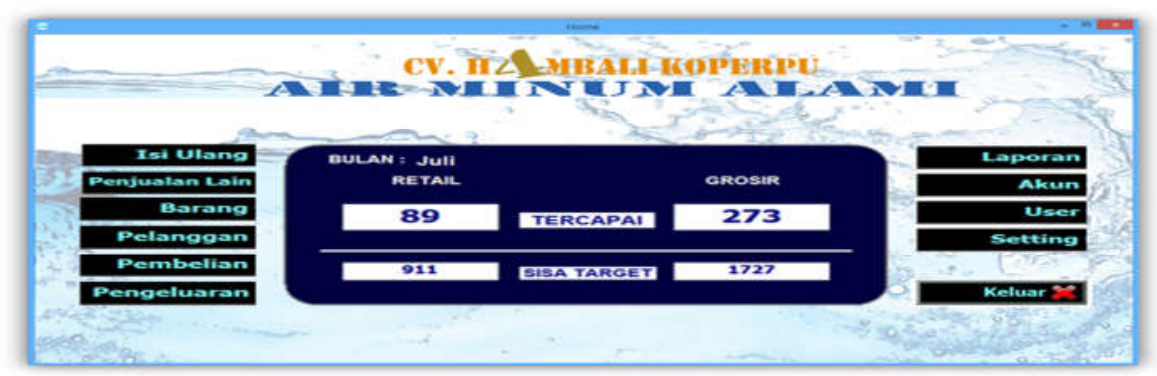

Gambar 8. Menu Utama

\subsection{Menu Transaksi}

Halaman menu transaksi merupakan tampilan utama untuk data detail transaksi mulai dari isi air ulang.

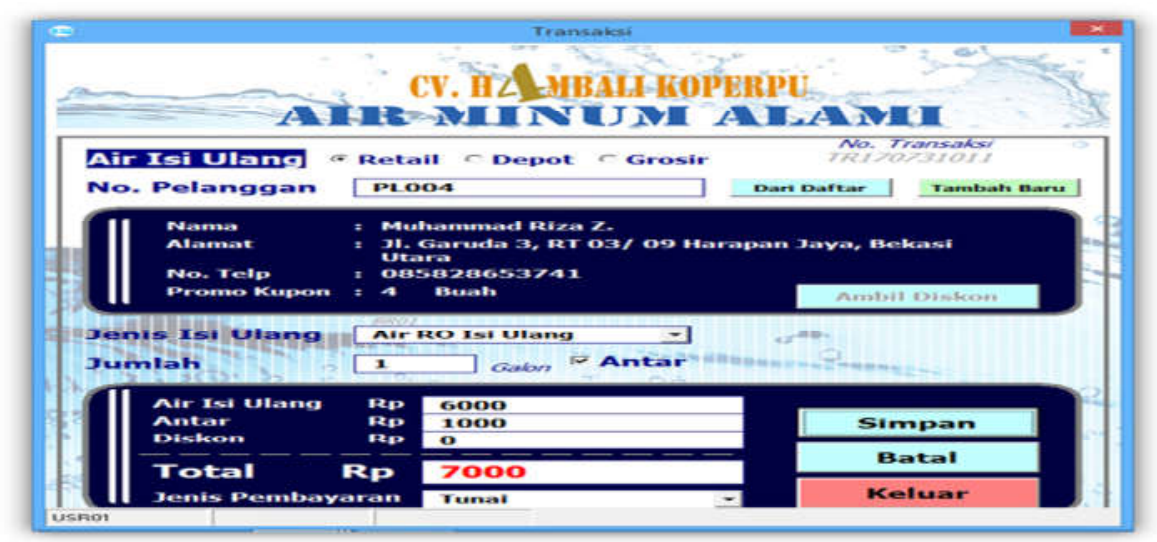

Gambar 9. Menu Trasaksi

\subsection{Menu Data Pelanggan}

Halaman menu data pelanggan ini merupakan tampilan untuk pengolahan data pelanggan.

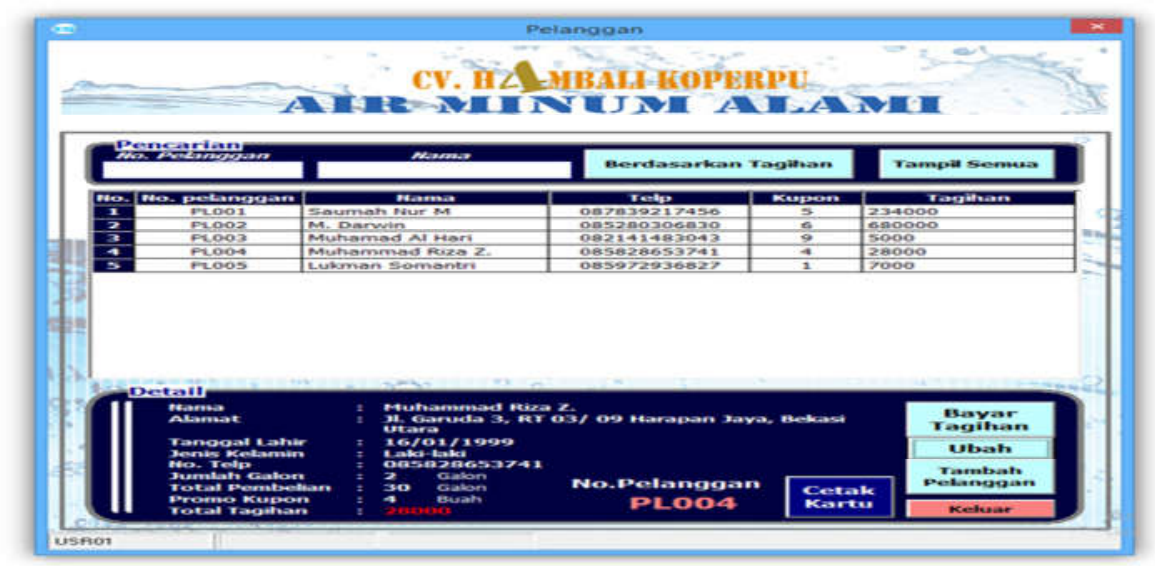

Gambar 10. Menu Data Pelanggan 
Jurnal Inkofar * Volume 1 No. 2, Desember 2018 * ISSN: 2615-3645 (Print) / 2581-2920 (Online)

Tersedia secara online di: http://www.politeknikmeta.ac.id/meta/ojs/

\subsection{Menu Data Barang}

Halaman menu data pelanggan ini merupakan tampilan untuk pengolahan data barang yang dibutuhkan untuk penjualan.

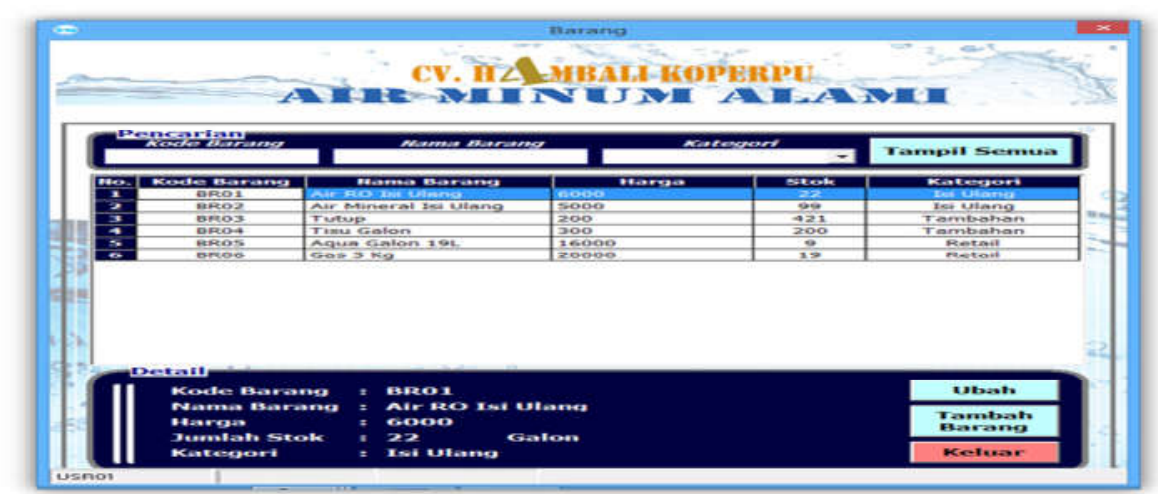

Gambar 11. Menu Data Barang

\subsection{Menu Laporan Transaksi}

Halaman menu laporan transaksi ini merupakan tampilan data transaksi untuk pengolahan semua laporan yang dibutuhkan.

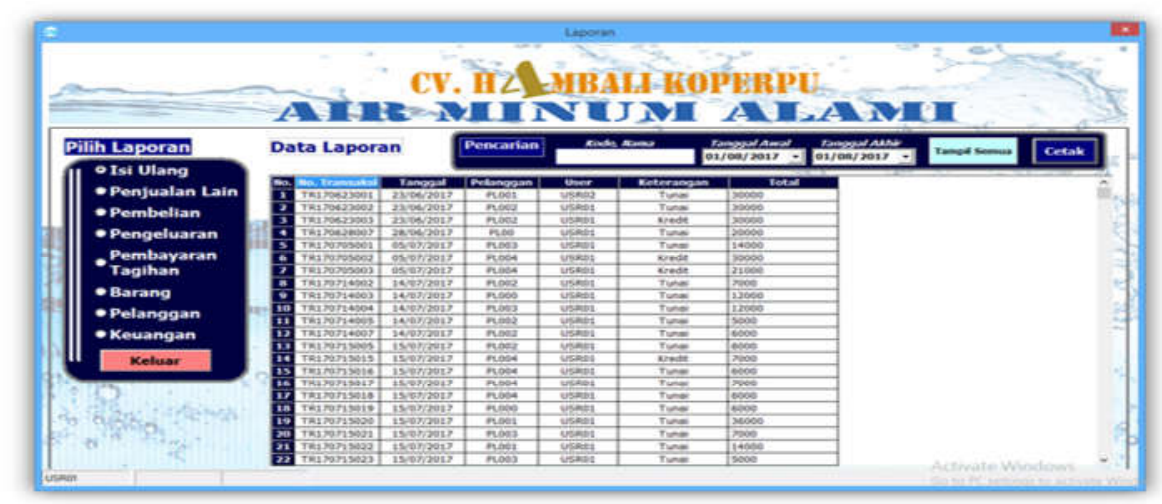

Gambar 12. Menu Laporan Transaksi

\subsection{Menu transaksi Pembelian bahan}

Halaman menu transaksi pembelian ini merupakan tampilan data transaksi untuk pembelian bahan bahan yang dibutuhkan untuk keperluan air isi ulang.

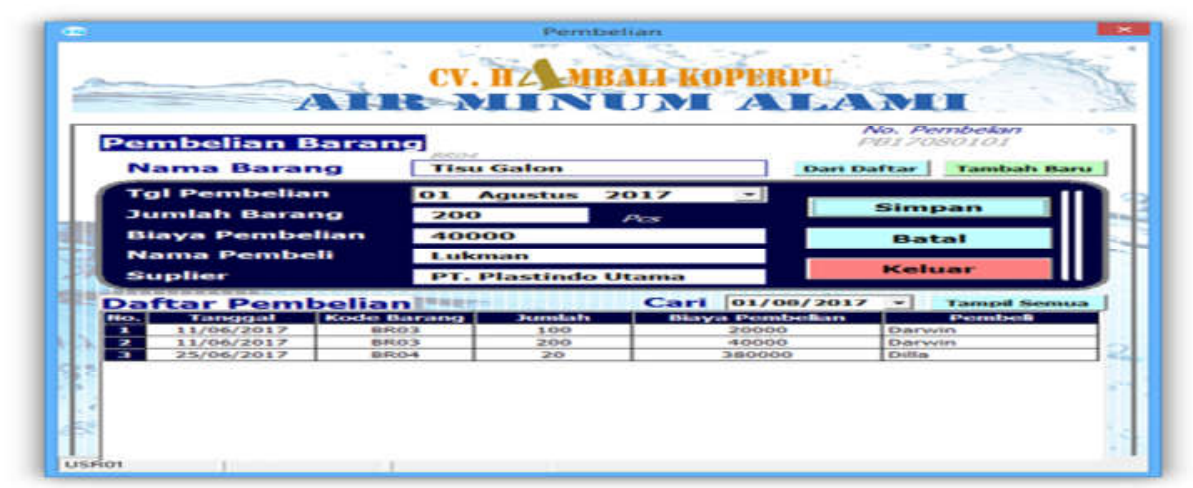

Gambar 13. Menu Pembelian Bahan 
Jurnal Inkofar * Volume 1 No. 2, Desember 2018 * ISSN: 2615-3645 (Print) / 2581-2920 (Online)

Tersedia secara online di: http://www.politeknikmeta.ac.id/meta/ojs/

\section{KESIMPULAN DAN SARAN}

Berdasarkan hasil penelitian dan pembahasan yang telah diuraikan pada bab-bab sebelumnya, maka dapat ditarik kesimpulan sebagai berikut:

a. Pengembangan sebuah aplikasi akan berjalan lebih baik lagi apabila diterapkan dengan program aplikasi berbasis android.

b. Aplikasi ini akan lebih menjadi sempurna jika data base yang dipakai dengan Oracle supaya daya tampung penyimpanan record-record besar.

\section{DAFTAR PUSTAKA}

Anhar. 2010. PHP \& MYSQL secara otodidak. Argomedia Pustaka. Jakarta.

Budi, Ronald. 2010. Programming with Microsoft Visual Basic 6.0. Yogyakarta: Skripta Media Creative.

Hutahean, Jeperson. 2014. Konsep Sistem Informasi. Yogyakarta : Deepublish

Kadir, Abdul. 2012. Algoritma \& Pemrograman Menggunakan Java. Yogyakarta: Andi Offset

Kamus Lengkap Dunia Komputer, Penerbit PT. Wahana Komputer dan Andi Yogyakarta.

Nazruddin Safaat H. 2012 (Edisi Revisi). Pemograman Aplikasi Mobile Smartphone dan Tablet PC Berbasis Android. Informatika. Bandung.

Pahlevi, Said Mirza. 2013. Tujuh Langkah Praktis Pembangunan Basis Data. Jakarta: PT Elex Media Komputindo.

Sunarfrihantono, Bimo. 2002. PHP dan MySQL untuk Web. Yogyakarta: Andi

Sukamto dan Shalahuddin. 2013. Rekayasa Perangkat Lunak. Bandung: Informatika. 